\title{
As agências de regulação dos serviços no Brasil e na França: transportes e telecomunicações
}

\author{
Anisio Brasileiro \\ Universidade Federal de Pernambuco, Brasil \\ Rômulo Orrico Filho \\ Universidade Federal do Rio de Janeiro, Brasil
}

\begin{abstract}
RESUMO: Este trabalho analisa, nos casos do Brasil e França, as experiências de criação de agências regulatórias nas redes de transportes e telecomunicações. A escolha dessas duas redes deve-se ao fato de que ambas passam por reformas regulatórias importantes, cobrem um leque variado de possibilidades de regulação, e são sujeitas a forte presença do Estado na sua provisão baseada na noção de serviço público. Mas os dois países vêm seguindo caminhos diferentes. A França busca uma terceira via, diferente da desregulamentação anglo-saxônica; o Brasil busca combinar as noções de serviço público e de public utility, com resultados até o momento pouco claros. O trabalho assim se estrutura. Inicialmente, põe-se a problemática conceitual em torno das reformas regulatórias nas redes sociotécnicas. Em seguida, busca-se reconstituir, em uma perspectiva histórica, os grandes momentos, nos dois paises, de privatizaçãoestatização-privatização com vistas a compreender os fatores culturais, econômicos e sociais que marcaram, desde seus inícios, as relações entre o Estado e as empresas privadas. Por fim, analisam-se as leis brasileiras e francesas de criação das agências de transporte e telecomunicações, ressaltando-se suas similitudes e diferenças.
\end{abstract}

ABSTRACT: This paper presents an analysis about Brazilian and French experiences in creating regulatory agencies for transport and telecommunication network services. The main reasons for this choice is the fact that both infrastructure cases have experienced important regulatory reforms, they also cover a wide range of regulatory possibilities; and services provision have allowed strong State presence based on public service conception. However, regulations in these countries are following different ways: France looks for a third manner, different from British deregulation; Brazil tries to combine public service and public utility concepts, reaching not very clear results until now. The analysis begins with a conceptual discussion about regulatory reforms in the field of infrastructural networks. Secondly, for both countries and from a historic perspective, the successive cycles of private and State ownership are examined, in order to understand the social, economic and cultural factors that shaped State and private companies relationships since early services. Finally, Brazilian and French transport and telecommunication agency creation laws are analyzed by outlining their similarities and differences.

\section{FRANÇA E BRASIL: QUE SIMILITUDES E DIFERENÇAS?}

As reformas regulatórias em andamento na Europa (Stoffaes, 1994) - em particular, França e Inglaterra - e no Brasil (Brasileiro e Aragão, 2000), nas redes de transportes e telecomunicações (também nas de água, energia e gás), vêm sendo acompanhadas, em geral, da criação de agências reguladoras independentes. Os ingleses criam então diferentes agências para regular os serviços das infra-estruturas prestados por grandes grupos privados em telecomunicações, gás, aviação civil, água, eletricidade e ferrovias. A experiência francesa, fortemente imbuída da noção de serviço público e do papel onipresente do Estado provedor, tem resistido à idéia de criação de agências, preferindo modernizar os operadores públicos dando-lhes o caráter de empresas comerciais, com a regulação se exercendo através dos ministérios de tutela. Todavia, recentemente, por conta de diretrizes da Comunidade Européia, foram criadas as ART - Agence de Régulation des Télécommunications e ARE-Agence de Régulation de l'Énergie, como uma forma, inclusive, de facilitar a articulação com as demais agências européias em políticas transnacionais.

Este trabalho analisa, nos casos da França e do Brasil, as experiências da criação de agências reguladoras nas aqui chamadas redes de comunicações - transporte ferroviário e telecomunicações. A escolha destas redes deve-se ao fato de que:

- ambas passam, desde meados dos anos 1990, por reformas regulatórias importantes - com a introdução de competição nos mercados, criação de agências reguladoras, privatizações ou modifi- 
cações na estrutura do operador histórico - que cobrem um leque variado de possibilidades de arranjos institucionais e regulatórios;

- no que concerne aos transportes, na França, separam-se as funções de gestão das infra-estruturas e das de operação, criando-se o Réseau Ferré Français-RFF, e mantendo-se a Société Nationale des Chemins de Fer - SNCF, operador histórico; no Brasil, o operador histórico, a Rede Ferroviária Federal - RFFSA, foi desmembrada em redes regionais, em seguida concedidas ao setor privado, e só posteriormente criada a ANTT - Agência Nacional de Transportes Terrestres, para a regulação dos contratos com as empresas. No âmbito local, no Brasil, embora agências reguladoras multisetoriais estejam sendo criadas, tais agências usualmente não abrangem o setor transportes, no qual é marcante a presença de órgãos gestores municipais e metropolitanos, de caráter mais próximo ao das Autorités Organizatrices francesas. Na França não há perspectiva de criação de agências locais;

- no que tange às telecomunicações, a França reestruturou a France Telecom, operador público histórico, mas não resistiu à pressão dos regulamentos pró-competitivos da Comunidade Européia e criou a Agence de Régulation des Télécommunications - ART, com limitados poderes regulatórios, entretanto, se comparada à autoridade de tutela, o Ministério das Telecomunicações. Já no Brasil, foi adotado um modelo semelhante ao anglo-saxão: a repartição da empresa pública, a TELEBRÁS, em redes regionais, em seguida concedidas a operadores privados, e criada a ANATEL - Agência Nacional de Telecomunicações, com fortes poderes em relação à autoridade de tutela, o Ministério das Comunicações.

Os procedimentos metodológicos usados neste trabalho buscam aproximar-se do método desenvolvido por Garièpy e Marié (1997), de olhar cruzado (regard croisé) baseado no diferencial de diversas abordagens oriundas da história, geografia, urbanismo e engenharia, nas origens territoriais das reflexões - Brasil e França -, afastando-se, todavia, da pura "comparação internacional" pois é dada grande importância aos elementos contextuais, exigindo-se assim uma reflexão sobre o tipo de olhar que cada país aporta.

\section{REFORMAS REGULATÓRIAS E COMPETIÇÃO}

Desde o final dos anos 70, profundo debate vem ocorrendo em torno do papel do Estado na provisão das redes econômico-sociais e técnico-territoriais. Conforme observa Curien (2000), os movimentos chamados de desregulamentação operam em três direções: (i) introdução da competição, pela liberalização ou abertura à concorrência de todo ou de parte do mercado; (ii) evolução do operador histórico, com eventual mudança de seu estatuto, do regime de propriedade de seu capital através de privatização global ou parcial, ou ainda sua recomposição orgânica pelo desmantelamento ou desintegração vertical; (iii) transformação da regulação, isto é, separação entre o exercício da tutela estatal e da operação da rede.

Esta terceira direção comporta, segundo o autor, duas dimensões: (a) política - defesa dos interesses nacionais, estratégias industrial e de política social -, no campo das prerrogativas do Estado tutelar; e (b) econômica - criação de um mercado concorrencial, atribuição de licenças e definição de cláusulas contratuais para os operadores -, que estaria sob a responsabilidade da autoridade administrativa independente, isto é, da agência reguladora. Esta abordagem é interessante, pois ela bem define o papel da agência reguladora enquanto indutora da competição no mercado, além do exercício das tarefas de fiscalizar e zelar pela qualidade dos serviços oferecidos aos usuários, atuando ainda como garantidora do cumprimento dos contratos. Ao poder de tutela, no caso os Ministérios, caberiam as missões de definidor das diretrizes, do planejamento e da formulação de políticas públicas. Este trabalho analisará, justamente, em que medida as experiências brasileira e francesa fornecem elementos para a confirmação dessa repartição de competências.

Da mesma forma, os estudos de Lévèque (1998) em torno da economia da regulamentação mostram que os processos de desregulamentação (ou de reforma das regulamentações, como prefere ele) comportam de um lado, a introdução da concorrência, e de outro, a separação entre o monopólio (o operador), o governo (a tutela) e o regulador (o organismo gestor ou a agência). É, assim, nesse segundo aspecto, que se explica a emergência da agência reguladora, justificada pela necessidade de assegurar a concorrência nos mercados. $\mathrm{O}$ exemplo francês é claro em revelar relações muito complexas entre organismo de tutela e operador histórico. Daí que a figura da agência autônoma parece tornar-se necessária, para assegurar que os concorrentes potenciais oriundos do setor privado gozem dos mesmos direitos e deveres do operador histórico.

\subsection{Origem e natureza do serviço público na França e no Brasil}

$\mathrm{Na}$ verdade, o debate sobre as reformas regulatórias tem como pano de fundo a redefinição do conceito de serviço público (Quin e Jeannot, 1997). Do ponto 
de vista histórico, o Estado francês sempre foi fortemente intervencionista, tendo sido desenvolvido desde o século XIX o conceito de serviço público juntamente com a idéia dos contratos passados entre o poder público e os operadores privados, sobretudo no caso das estradas de ferro. Segundo Musso (1997), a cultura de intervenção do Estado na provisão das redes técnicas remonta aos saintsimoniens. De fato, a obra de Saint-Simon Vues politiques et pratiques sur les travaux publics en France, publicada em 1832, colocou a famosa "thèse des trois thèses" balizadora da regulação das redes de comunicação - transportes e telecomunicações. Toda liberdade ao mercado; ou todas as atividades realizadas pelo Estado; ou concessão outorgada às companhias privadas com subvenções do Estado: das três teses é a última a que tem prevalecido ao longo da história das relações público-privado na provisão das redes sociotécnicas na França.

No século XX, o conceito de serviço público, peça chave do direito administrativo francês, foi aperfeiçoado pela famosa escola do serviço público (ou Escola de Bordeaux), destacando-se Duguit, Jèze e Bonnand, os quais sistematizaram uma doutrina do serviço público: ligada às idéias de solidariedade social, utilidade pública, interesse geral; definida pelos princípios de continuidade, igualdade, adaptação, neutralidade, transparência.

Distinguem-se na França dois modelos de serviço público: os nacionais, diretamente ligados ao Estado, tais como ferrovias, telefonia, energia, gás, correios, cujos serviços são prestados pelo Estado, respectivamente por meio das operadoras públicas SNCF, France Telecom, EDF, Gás de France, La Poste; e os locais, prestados por uma empresa pública municipal (régie) ou delegados a sociedades privadas, através de contratos de concessão com maiores (régie intéréssée) ou menores riscos (affermage) dos concessionários.

No Brasil, a noção de serviço público, presente desde a Constituição de 1937, segue em linhas gerais o modelo francês. Seu conteúdo pode ser resumido da seguinte forma: em atividades consideradas essenciais, o Estado chama para si a competência da execução, devendo-se garantir que todos os cidadãos tenham direito a acesso, independentemente de condições sociais e geográficas. Portanto, o serviço há de ser prestado de forma ubíqua e regular, a um preço acessível. Além disso, ele deve ser permanentemente atualizado (ver Art. $6^{\circ}$ da Lei $n^{\circ} 8.987 / 95$ ). Sua execução pode se dar tanto por uma entidade pública quanto por uma empresa privada, mediante contrato administrativo. Por este, o contratado é obrigado a realizar o serviço conforme as orientações e planejamento do Poder Público, cobrando as tarifas por ele determinadas, mas fazendo jus a um equilíbrio econômico do contrato (Aragão, 1998).

É justamente este conceito unitário e homogêneo, de serviço público que, no bojo das reformas regulatórias em curso, é posto em xeque. Daí porque se avança a hipótese da fragmentação do conceito unitário de serviço público em uma multiplicidade de sistemas de ações e de princípios de regulação, que não podem ser reunidas sob um conceito único. A ruptura atual, ou o ponto principal em questão, não seria o surgimento de um novo modelo, alternativo ao conceito de serviço público, mas sim, a desestruturação da idéia do conceito único, do papel unificador da noção que predominou até recentemente. Dessa forma, as transformações dos modos de regulação das redes sociotécnicas não apontam para uma estrutura única. Ao contrário, sinalizam para várias estruturas de ação, segundo as formações sociais, mas também no ambiente interno de um país, segundo os domínios e no interior de cada domínio. É essa idéia de fragmentação do conceito de serviço público que tentaremos visualizar na análise das experiências francesas e brasileiras.

\section{MARCOS DA EVOLUÇÃO DAS RELAÇÕES PÚBLICO-PRIVADO NAS REDES DE COMUNICAÇÕES}

A compreensão dos grandes marcos da intervenção do Estado nas atividades econômicas e nas redes de comunicações, bem como da própria evolução do conceito de serviço público, necessita uma análise diacrônica, baseada no longo prazo. Aliás, o estudo da evolução dos modos de regulação das redes sociotécnicas ou dos "macro-sistemas técnicos" necessita obrigatoriamente de uma análise no longo prazo, através dos movimentos sincrônico e diacrônico, como bem atesta o trabalho de Coutard (1998). Para as análises históricas, é imprescindível o estabelecimento de uma periodização, que não deve ser vista de forma rígida e linear, pois os fatos históricos se originam em períodos anteriores e a sua compreensão só pode ser feita nos períodos futuros. Isto posto, desenvolvemos a seguir uma breve caracterização da evolução das redes de comunicações, na França e no Brasil, colocando em evidência os movimentos de privatização-estatização ou estatização-concessão da provisão das redes ao setor privado.

\subsection{Das origens privadas às estatizações do pós- guerra}

Na França, o primeiro fato marcante nas telecomunicações ocorreu em 1790, com a invenção do telégrafo ótico por Claude Chappe. Entre os anos 1793 e 1823 é a empresa dos irmãos Chappe que gerencia 
o telégrafo, mas atendendo apenas ao Governo para fins militares, sob tutela do Ministério da Guerra e depois pelo do Interior (Flichy, 1997; Musso, 1997). Em 1832, Alexandre Ferrier lança uma subscrição para constituir o capital privado de uma empresa de telégrafo para ligar as principais cidades européias, chegando a construir uma linha entre Paris e Rouen (Flichy, 1997).

Mas, em maio de 1837 , verifica-se a primeira estatização, ocorrendo também, segundo Musso (1997), o primeiro grande debate sobre a regulação do setor, no contexto da thèse des trois thèses. O telégrafo ótico se inscreve, segundo Flichy (1997), na continuidade de uma evolução, a do transporte de correspondências. Uma rede de grandes eixos com pavimentos resistentes se constrói para a circulação a galope. Em 1775, é criada a Régie das diligências e correspondências (messageries). Mas até o século XVIII as estradas francesas eram de terra; além disso, apenas em 1738 surge uma primeira classificação hierárquica das estradas na França.

Mas o desenvolvimento dos transportes e dos telégrafos ótico e elétrico e, depois da telefonia, só foi possível graças ao avanço tecnológico da eletricidade com o surgimento da pilha elétrica em 1800, a descoberta do eletromagnetismo em 1820, e as primeiras experiências de exploração comercial do telégrafo elétrico em 1837. A linha Paris-Lille foi construída em 1840 (Flichy, 1997). O telefone surge em 1880, com sua operação sendo confiada durante o curto período de dez anos a uma empresa privada, a Société Générale du Téléphone. Todavia, em 1889 , o telégrafo é novamente estatizado, desta vez em definitivo.

Em 1920, a partir de relatório elaborado por Henri Fayol, produz-se um novo discurso estruturador para o setor (Musso, 1997). Suas críticas se concentram sobre as condições de funcionamento dos PTT-Postes, Telégraphes et Télécommunications, que era ao mesmo tempo órgão de tutela e operador. Ele observa a ausência de um programa de ação de longo prazo, e a ausência de recompensa por serviços prestados. Propõe a gestão dos PTT como uma empresa privada. Suas críticas levam à adoção de uma forma híbrida de serviço público industrial e autônomo, com a administração se dotando de um orçamento anexo dos PTT, pela Lei das Finanças de 1923. Segundo o autor, esta Lei tem um efeito duplo: negativo, pois o telefone não se desenvolverá rápido; positivo, pois ela estabiliza o quadro legislativo até 1990. Mas a Lei não resolve o financiamento do telefone e o problema vai eclodir nos anos 60 , quando os engenheiros de telecomunicações - conscientes do atraso da França - vão se mobilizar para que o Estado financie, enfim, o telefone (Musso, 1997).
Ainda na França, a história das comunicações terrestres e, em particular, do transporte ferroviário, está ligada à formação do Corpo de Ponts et Chaussées, isto é, dos engenheiros do Estado. O Corpo foi criado em 1716, com o objetivo de elaborar projetos e executar obras públicas (Caron, 1997). Na época, grande importância era dada à construção de vias navegáveis e entre 1750 e 1789 foram construídos $387 \mathrm{~km}$ de canais. Mas aos poucos a ideologia hidroviária foi substituída pela ferroviária; e para que a ferrovia se desenvolvesse era necessária a existência de homens de negócios e de banqueiros capazes de reunir o capital necessário à construção, pois o Estado não podia arcar sozinho. Surgem então os "grandes banqueiros do século XVIII", que mantinham fortes relações com o nascente mundo industrial e com o próprio Estado. A constituição, no início dos anos 1840, de uma indústria de material ferroviário e de locomotivas permitiu a interligação entre estas dimensões dos saberes técnicos (Caron, 1997).

Através de um Decreto Real de 1823, nascia a primeira ferrovia em 1828, entre Andrézieux e SaintEtienne, com 23 km (Ribeill, 1993). Os seus principais acionistas tinham negócios nas minas de ferro e na siderurgia da região. Era assim tipicamente uma ferrovia mineira, construída e operada por capitais privados. Em 1832, com os irmãos Seguin, nascia uma ligação a tração animal entre Saint-Etienne e Lyon, com $56 \mathrm{~km}$, embora eles tivessem comprado duas locomotivas Stephenson em 1826, na Inglaterra. Neste período, concessões à perpetuidade são dadas, através de atos do Rei, a companhias privadas. Em 1837 nascem as ferrovias de Paris a Versailles e Paris a Saint Germain. Até 1842, concessões diversas a empresas privadas foram acordadas pelo Governo.

Conforme observa Ribeill (1993), o modelo de financiamento das ferrovias era assim repartido: dois terços dos custos de expropriação provinham dos departamentos e cidades envolvidos, o Estado financiava o outro terço e a infra-estrutura da via; às companhias privadas incumbia a superestrutura (compra e colocação dos trilhos e balaústres), o material rodante, a operação e manutenção das ferrovias. Mas o Estado decidia sobre as tarifas e a extensão das linhas. O projeto foi transformado em Lei em 11 de junho de 1842, passando a ser conhecido como a carta dos caminhos de ferro franceses.

Uma lei de 1845 abolia a participação dos departamentos e cidades (communes) na compra dos terrenos. Em 1842 o Estado assumia pela primeira vez a operação ferroviária, ao construir e operar a linha de Lille a Valenciennes na fronteira belga (Ribeill, 1993). Em 1847 ocorriam as primeiras falências de companhias e a primeira fusão se verificava, ao mesmo tempo em que o Governo estabelecia 
cláusulas contratuais cada vez mais restritivas para o capital privado. Assim, entre 1832 a 1865, Ribeill constata a presença de seis grandes companhias ferroviárias privadas, junto com pequenas empresas de "interesse geral".

No decorrer dos anos 1930, a crise econômica afetava as empresas. Por outro lado, a chegada da esquerda ao poder, através da Frente Popular, em 1936, contribuiu para a estatização das empresas privadas. Em 1938, nasce a Société Nationale des Chemins de Fer-SNCF, sociedade anônima de capital misto, $51 \%$ pertencendo ao Estado e $49 \%$ aos acionistas das companhias privadas até então existentes.

No Brasil, a exemplo das demais infra-estruturas em rede, a provisão dos serviços de telefonia - construção, operação e manutenção - é concedida ao setor privado, a maioria empresas de origem estrangeira. Assim, o primeiro aparelho telefônico teria sido instalado em 1877, no Palácio São Cristóvão, no Rio de Janeiro, utilizando uma linha até o centro da cidade, pela Western and Brazilian Telegraph Company.

Com o crescimento da demanda, em 15 de novembro de 1879, um Decreto imperial outorgava a primeira concessão para a exploração dos serviços no Brasil. O beneficiário era Paul Mackie, representante dos interesses da Bell Telephone Company, que recebia licença para construir e operar linhas telefônicas entre a capital do Império e a cidade de Niterói. Nos anos seguintes, inúmeras concessões foram outorgadas nas várias regiões do país. Com a República em 1889, o Estado passou a exercer um maior controle sobre os valores cobrados pelos serviços. Em 26 de fevereiro de 1890, os preços passaram a ser fixados pelo Estado.

Nos anos seguintes, com o desenvolvimento econômico e com o crescimento das cidades, a demanda cresceu mais ainda, e a cidade de Porto Alegre foi a primeira do Brasil a inaugurar uma central automática, em 1922. Nas décadas seguintes, e em especial no início da década de 1960, os serviços foram prestados por uma multiplicidade de operadores (prefeituras, pequenas empresas privadas e cooperativas), com hegemonia do setor privado. Especificamente, em 1962, a empresa telefônica subsidiária da Canadian Tractions Light and Power Company operava $62 \%$ das linhas telefônicas do país; os restantes 38 $\%$ eram atendidas pelos municípios e pequenas empresas privadas.

No Brasil, no setor de transportes, todo o período que vai da segunda metade do século XIX aos anos 1940, é dominado pelo setor ferroviário, em um contexto em que prevalecia a economia exportadora de produtos primários (Brasileiro e Henry, 1999).
Ligados aos portos, os trens viabilizavam a exportação desses produtos em troca de bens de capital e produtos industriais europeus e norte-americanos. Leis de 1852 e 1872 favoreciam a entrada de capitais estrangeiros, sobretudo ingleses, para viabilizar a expansão ferroviária por intermédio de garantia de juros, subvenção por quilômetros construídos, concessões de longo prazo e monopólio da operação, dentre outros. Assim, do final do século XIX até a primeira Guerra Mundial, tem-se o período em que mais se constrói ferrovias no país. Foram 12.386 $\mathrm{km}$, um terço do que seria o tamanho máximo da rede $(38.170 \mathrm{~km})$, alcançado em 1960.

No Brasil, as ferrovias nascem e se desenvolvem através do setor privado, com a constituição de empresas, associando capitais brasileiros, oriundos da nascente indústria e, sobretudo, de origem estrangeira: ingleses, franceses e canadenses. Por meio de concessões e em regime de monopólio por 50 a 90 anos, estas companhias construíam e operavam as redes de infra-estrutura do país e das cidades, tais como iluminação, saneamento, telefonia, gás, bondes elétricos. Esse modelo é hegemônico em todo o país até os anos 1940, quando começa a se desenvolver o transporte rodoviário, já sob a influência da indústria automobilística e dos capitais norte-americanos, em detrimento dos capitais ingleses (Brasileiro, 1981).

Todavia, observe-se que da mesma maneira que o Governo francês construiu uma ferrovia, em 1842, entre Lille e Bruxelas, o Governo brasileiro também construiu a sua, em 1878: a famosa Estrada de Ferro Dom Pedro II, ligando o Rio de Janeiro a São Paulo. Isto significa que, mesmo naquele primeiro marco das construções ferroviárias, hegemonizadas pelo capital privado, havia uma intervenção estatal, seja regulando os serviços através da fixação das tarifas e da outorga das concessões seja, embora residualmente, construindo e operando uma ferrovia.

Ainda no Brasil, sobretudo nos dois períodos Vargas (1930-1945 e 1950-1954), põe-se em prática uma política nacional desenvolvimentista, na indústria pesada - siderurgia, aço, mineração - com a criação de empresas estatais tais como a CSN - Companhia Siderúrgica Nacional (1946) e a Petrobrás (1952). Nos transportes, o Governo cria todo um conjunto de instrumentos organizacionais e financeiros, tais como o Departamento Nacional de Estradas de Rodagem - DNER, em 1946, e o Imposto Único sobre Lubrificantes e Combustíveis (1940), para dar suporte à expansão rodoviária que viria a ocorrer nos anos 1950 a 1970 . No setor ferroviário, o Governo cria em 1941, o Departamento Nacional de Estradas de Ferro - DNEF, e passa, nos anos seguintes, a utilizar parte das indenizações recebidas pelo país em função de sua participação na II Guerra Mun- 
dial, para pagar as indenizações das encampações das ferrovias privadas cujas concessões findavam. Finalmente, a estatização completa das ferrovias ocorreu em 1957, com a criação da Rede Ferroviária Federal - RFFSA, exatamente vinte anos após sua análoga francesa.

Em suma, tanto no caso francês quanto no brasileiro, o primeiro momento de expansão das redes de comunicações - transporte ferroviário e telefonia - é marcado pelo duplo regime, de participação do capital privado na construção, operação e manutenção das infra-estruturas, mas submetido ao controle do Estado. Se bem que o controle e a presença estatal já é muito mais forte na França, país que construiu - e inclusive exportou para o Brasil - toda uma cultura e um direito administrativo baseado nas concessões dos serviços públicos ao setor privado.

\subsection{Do pós-guerra aos anos 1980: gestão e operação estatais}

O Pós-Guerra caracteriza-se na França pela constituição do Estado keynesiano. Em dois anos, 45-46, o Estado torna-se o principal investidor do país, estatizando bancos e eletricidade, bem como as Usines Renault (1945), e a Compagnie Générale Transatlantique (1948).

Neste contexto, Ribeill (1993) afirma que entre o Pós-Guerra e 1981 a SNCF foi crescendo em torno das ambigüidades de seu estatuto de sociedade híbrida, tendo que conciliar serviço público e equilíbrio econômico. Entre as Leis de 31 de agosto de 1937 e a publicada em 27 de julho de 1971, o Estado e a SNCF vão estar ligados por dois Contratos de Programa e por um Contrato de Empresa que já traduzem um certo desengajamento do Estado em relação à concepção tradicional de serviço público ferroviário. Em 1982, a SNCF é transformada, já sob influência da LOTI - Lei de Orientação dos Transportes Interiores, em estabelecimento público de caráter industrial e comercial. Este é um momento importante da ferrovia, com a entrada em operação do $\mathrm{TGV}$, em concorrência com o transporte aéreo.

Quanto às telecomunicações francesas, segundo Musso (1997), no início dos anos 1960, a constatação é unânime que o Orçamento Anexo de 1923 não cumpriu suas promessas. Assim, da mesma forma que no segundo império sob impulso saint-simonienne, o Estado industrialista vai ser chamado, pelo corpo de engenheiros de telecomunicações, a intervir fortemente no setor. Em meados dos anos 1960, o Governo francês toma a decisão política de acelerar o desenvolvimento do telefone. Um plano de recuperação é posto em prática e, em 15 anos, a França constrói a rede mais digital do mundo.
Vale salientar a importância do Relatório elaborado em 1978, por Simon Nora e Alain Minc, intitulado L'Informatisation de la Société. Segundo Musso, os autores definem uma nova rede, a "telemática", fruto da convergência da informática e das telecomunicações, anunciando uma "sociedade da informação". Neste quadro de emergência de uma "sociedade de comunicação" coloca-se como prioritária a mudança do estatuto da Direction Générale des Télécommunications - DGT, operador público pertencente ao Ministério das PTT. Assim, o Estado francês, ao contrário do que fez com os transportes e energia - criando as empresas públicas SNCF e EDF, respectivamente -, não cria uma empresa específica para operar o setor. A tutela e a operação da telefonia são executadas, conjuntamente, pela DGT e pelo próprio Ministério.

No Brasil, nos anos de 1950 a 1979, ocorre uma industrialização acelerada, impulsionada pela indústria automobilística e com a forte presença do Estado na economia. Nas décadas de 60 e 70, época dos governos militares, põe-se em prática planos nacionais de desenvolvimento econômico, em um contexto de forte intervenção estatal nas infra-estruturas básicas com grandes empresas operadoras federais e estaduais. Tratava-se da implantação de um sistema centralizado e hierarquizado, em que os municípios tinham pouco ou quase nenhum poder.

No setor das telecomunicações, ainda nos anos 50 , os municípios eram encarregados da tutela sobre os serviços de telefonia, operados por empresas privadas. O sistema era bastante precário, por falta de investimentos, e com débil cobertura territorial. Mas, nas décadas de 60 e 70, no contexto acima, o Governo Federal intervém no setor, criando em 1962, o Código Nacional das Telecomunicações, e em 1965 a Embratel, estatal operadora interurbana e internacional. Em 1972, criava-se o Ministério das Telecomunicações e a holding Telebrás, que passou a centralizar as políticas das empresas estaduais.

No Brasil, nos transportes, o setor ferroviário passa a sofrer uma crescente concorrência do rodoviário. Como resultado, tanto no transporte de cargas quanto no de passageiros, verifica-se um implacável decréscimo do modo ferroviário. Nas cidades, emerge uma política nacional de transportes urbanos, com a criação de organismos estatais: no plano nacional, a EBTU - Empresa Brasileira de Transportes Urbanos, nas Regiões Metropolitanas, as EMTU-Empresas Metropolitanas de Transportes Urbanos e nas capitais, as superintendências, empresas ou companhias operadoras municipais de transportes urbanos. Nesta época de forte intervenção estatal, surge a CBTU-Companhia Brasileira de Trens Urbanos, para coordenar e operar os trens metropolitanos do Recife, Belo Horizonte 
e Porto Alegre, formando com a RFFSA, gestora e operadora dos trens de subúrbio, o sistema estatal de transportes sobre trilhos (Brasileiro e Henry, 1999).

Em suma, nos transportes, este segundo momento da evolução das ferrovias é radicalmente diferente nos dois países. Em ambos, ocorreu uma poderosa expansão do modo rodoviário, a construção de estradas permitiu a ligação de todos os cantos do país, acompanhadas pela criação de organismos técnicos nacionais e de toda uma capacitação profissional. Isso em conseqüência da criação, nos dois países, de um imposto incidindo sobre o consumo de combustíveis, resultando daí a existência de um fundo nacional para construção de rodovias. Mas, a diferença essencial entre ambos reside no lugar ocupado pela ferrovia. Na França, não se observou o desmantelamento do modo ferroviário, que sempre contou com o forte apoio do Governo, contrariamente ao Brasil, que fez, desde o pós-guerra, a opção rodoviarista.

Nas telecomunicações, as semelhanças são maiores, pois ambos tomam a decisão política de desenvolver tecnologicamente a telefonia, implantando toda uma estrutura estatal para construir, operar e manter este setor. Mas, pode-se dizer que, tanto nas telecomunicações quanto no transporte ferroviário, o traço predominante deste segundo momento (do pós-guerra aos anos 1980) é a forte presença estatal, centralizada e com pouco ou nenhum poder dos municípios sobre estas redes, tanto na construção, quanto na operação das comunicações. Observe-se, todavia, que em ambos os países, a responsabilidade pelos transportes públicos urbanos, sempre esteve ao encargo das municipalidades, fato este que confere mais um ponto de interesse na confronto entre os modos de gestão.

\subsection{Anos 1980 - 1990: a terceira via francesa e as privatizações brasileiras}

Nas telecomunicações, ocorre em 1982 nos EUA, o início das reformas regulatórias com a publicação do decreto que autorizou a ATT - American Telegraph and Telephone a entrar no mercado mundial de telecomunicações e na indústria de informática. Mas o dia $1^{\circ}$ de janeiro de 1984 , dia do desmantelamento de $A T T$, torna-se a data simbólica que marca o início da desregulamentação no mundo (Walrave, 1995). $\mathrm{Na}$ Inglaterra, por exemplo, no final dos anos 1970, o serviço telefônico estava degradado, o que contribuiu para o governo Thatcher aplicar as políticas de privatização. Assim, a BT - British Telecom, empresa pública, sob a tutela do Ministério da Indústria, foi separada do Post Office em 1981. Em 1982, a BT foi posta sob concorrência por Mercury - empresa privada criada em 1981 por iniciativa do próprio governo -, na rede internacional.
Neste contexto, na França, na década de 1980, a desregulamentação das telecomunicações - limitação ou supressão do monopólio público - não é discutida (Musso, 1997). Todavia, em 1982, a questão aparece no sistema audiovisual, com a Lei sobre a comunicação audiovisual. Esta lei mantém o controle do Estado sobre as infra-estruturas e introduz a concorrência nos serviços telemáticos. Mas, em 1985, o debate sobre a desregulamentação irrompe com força na França. Musso (1997) define este debate nos seguintes momentos: emergência do tema da desregulamentação na DGT (1984-86); quebra do monopólio de 1837 (1986-87); separação da tutela e operação, entre o Ministério das PTT e France Telecom, que passa a ter autonomia jurídica em relação ao Estado (1989-90).

Em 1993, o Conselho Europeu dos Ministros das Telecomunicações decide desregulamentar todos os serviços de telecomunicação a partir de $1^{\circ}$ de janeiro de 1998. Posteriormente, em 1996 são publicadas duas Leis relativas à regulamentação das telecomunicações, à criação da ART - Autoridade de Regulação das Telecomunicações e de uma Agência Nacional de Gestão de Freqüências Radioelétricas, e à modificação do estatuto da France Telecom.

Quanto ao operador histórico, ainda em 1988, a DGT se transforma em France Telecom e em 1990, em operador público. Entre 1991 e 1996, é um operador público (uma espécie de autarquia), separado do Ministério e, em 1997, torna-se sociedade anônima, com capital majoritário do Estado.

No setor ferroviário, a diretiva européia 91/440 da OCDE buscou incentivar os Estados nacionais a adotarem diretrizes de desengajamento, apontando para (Bergougnoux, 2000): reforçar a autonomia de gestão das empresas ferroviárias e saneá-las financeiramente; favorecer o aparecimento de concorrência, abrindo a infra-estrutura ferroviária a outros operadores e impondo a separação, ao menos contábil, entre os serviços e a infra-estrutura; adotar o princípio de cobrança pelo uso da infra-estrutura.

Mas na Inglaterra, ainda em 1982, iniciou-se a reforma regulatória no setor ferroviário, com a reorganização da British Railway. Em 1993, mais de dez anos depois, foi publicado o Railway Act para preparar a privatização por etapas, separando de início a infra-estrutura (via férrea e estações) dos serviços, privatizando em seguida diversos setores. Desde 1994, o setor de fretes foi aberto à entrada de novos operadores. Atualmente, a regulação é assegurada pelo Office of Rail Franchising, que atribui licenças, zela pelas regras da concorrência, fixa tarifas de uso das infra-estruturas e acorda subvenções às linhas não rentáveis. Em paralelo, Rail Track foi constituída como empresa autônoma para gerir as infra-estruturas e sua manutenção. 
Neste contexto de pressão da Comunidade Européia para o desengajamento do Estado na provisão das infra-estruturas em rede, a França busca uma terceira via, tanto nas telecomunicações - com a reorganização e o fortalecimento do operador histórico, em lugar de sua privatização - quanto no setor ferroviário. A busca desta terceira via constitui-se, pois, em uma opção política do Governo e da sociedade francesa. Resumindo, a SNCF foi criada em 1938, com o Estado detendo 51\% do capital, os 49\% restantes repartidos entre as antigas companhias, reduzidas progressivamente, a um papel menor. Ao expirar o contrato, em 1983, a LOTI transformou a SNCF em um estabelecimento público industrial e comercial, que recebeu em dotações os bens imobiliários anteriormente concedidos à sociedade anônima. Após 1995, as reformas no setor ferroviário se deram em duas direções.

Em primeiro lugar, a clarificação das responsabilidades respectivas do Estado e da SNCF. Ou seja, a separação das relações entre tutela e operação. A tutela sobre o setor fica no Ministério dos Transportes, enquanto a operação permanece com a SNCF. O Estado fixa a consistência e as características principais da rede ferroviária nacional. Um novo estabelecimento público do Estado, a RFF-Réseau Ferré de France assume a responsabilidade das infra-estruturas ferroviárias, de seu desenvolvimento e de seu financiamento e também assume os custos da dívida da infra-estrutura da SNCF. Em contrapartida, torna-se proprietária, em lugar do Estado, da infra-estrutura ferroviária. Nesse novo modelo, de clara separação entre as tarefas de tutela, gestão das infra-estruturas e operação, a SNCF permanece uma empresa única, seu estatuto e pessoal não se alteram. Ela assegura a manutenção e a operação da rede por conta da RFF segundo objetivos e princípios que esta fixa.

No quadro da LOADT - Lei de Orientação para o Ordenamento e Desenvolvimento do Território, buscou-se implicar diretamente as Regiões na organização e financiamento do transporte de passageiros. As Regiões tornam-se Autoridades Organizadoras e passam a receber uma ajuda financeira do Estado que antes as versava à SNCF.

Neste novo modelo organizacional, a RFF é um organismo do Estado cujas regras contábeis e métodos de gestão são os mesmos das empresas industriais e comerciais. Ela propõe ao Estado - a partir da identificação das necessidades - as adaptações que lhe parecem necessárias. Define as modalidades de programação, de financiamento e da realização dos investimentos necessários. A RFF é proprietária da rede ferroviária e confia sua manutenção à SNCF e a remunera para isto. Estas missões se efetuam no quadro de uma convenção passada entre os dois organismos. Ela confia ainda à SNCF a gestão quotidiana da rede, que se encarrega dos projetos de linhas dos TGV e de linhas novas. Quanto ao seu modo de funcionamento, a RFF constitui equipes compostas de agentes da SNCF, de funcionários cedidos e de profissionais oriundos do setor privado. Seu efetivo era de 55 pessoas em 1997 e 111 em 1998. Ela cria ainda representantes regionais, através de acordos com as coletividades locais.

Eis as principais orientações da RFF: (a) prioridade ao transporte de cargas; (b) favorecer a criação de corredores europeus de frete; (c) continuar o desenvolvimento das linhas a grande velocidade; (d) melhorar a rede existente; (e) responder às expectativas das regiões. Isto através de uma política de participação e de escuta dos atores políticos, econômicos e sociais regionais.

No Brasil, o processo de privatização das infraestruturas, enquanto parte integrante das reformas econômicas do Governo, teve início efetivamente com a criação do PND - Programa Nacional de Desestatização, em 1990. Nos primeiros anos, o PND concentrou esforços na venda de estatais produtivas, pertencentes a setores anteriormente estratégicos, a exemplo da siderurgia e petroquímica. A partir de 1995, a privatização passa a ter maior prioridade ainda, com a criação do CND - Conselho Nacional de Desestatização, e as concessões das infra-estruturas públicas passam ao setor privado. A agenda inclui eletricidade, telecomunicações e transportes (Brasileiro e Aragão, 2000).

Ao mesmo tempo põe-se em prática processos de desestatização das empresas estaduais, a exemplo da Cia. Riograndense de Telecomunicações e da Cia. de Eletricidade de Minas Gerais. Em 1997, teve início a privatização do setor de telecomunicações, com as licitações das concessões de telefonia móvel celular e com a aprovação da Lei Geral de Telecomunicações. Em 1998, o governo federal vendeu as $12 \mathrm{hol}$ dings, criadas a partir da cisão do Sistema Telebrás, representando a transferência à iniciativa privada, das empresas de telefonia fixa e de longa distância, bem como das empresas de telefonia celular.

A desestatização no setor de transportes toma vulto com a implantação, em 1993, do PROCROFE - Programa de Concessões de Rodovias, estabelecido através de portaria do Ministério dos Transportes. Em sua primeira etapa, o programa incluiu os trechos que tinham sido objeto de pedágio pelo próprio DNER: em 1994, a ponte Rio-Niterói (14 km); em 1995 as rodovias Rio de Janeiro-Juiz de Fora, $(180 \mathrm{~km})$, Rio de Janeiro-Teresópolis $(45 \mathrm{~km})$ e Rio de Janeiro-São Paulo (407 km); em 1997 a rodovia Porto Alegre-Osório com $112 \mathrm{~km}$. Em paralelo, programas de concessões rodoviárias foram feitos nos 
estados de São Paulo, Paraná, Santa Catarina, Rio de Janeiro, Rio Grande do Sul e Minas Gerais.

No setor ferroviário de cargas, a malha nacional sob a tutela da RFFSA foi repartida em seis regionais e submetidas a leilão, e concluída a desestatização em 1997, com a concessão da malha Nordeste. Daí em diante, nos transportes urbanos de passageiros, privatizaram-se operadores públicos, tanto no modo ferroviário (Flumitrens e Metrô, no Rio de Janeiro), quanto no rodoviário (CMTC/SP, EMT-Santo André e João Pessoa, CTC-Rio de Janeiro, TRANSURBSalvador e CTU-Recife) e até no hidroviário (CONERJ, no Rio de Janeiro). Neste último caso incluise o arrendamento do terminal de Contêineres do Porto de Santos e a transferência à iniciativa privada da exploração do Terminal de Contêineres do Porto de Sepetiba, das Companhias Docas do Rio de Janeiro e Espírito Santo, do Terminal roll-on-roll-of do Rio de Janeiro e do Porto de Angra dos Reis.

Esse é, pois, o contexto institucional no qual emergem, na França e no Brasil, as agências reguladoras, elas mesmas como se viu, parte integrante destas reformas que redefinem o papel do Estado na provisão das redes sociotécnicas. Vejamos as principais semelhanças e diferenças entre as agências francesas e brasileiras.

\section{AS AGÊNCIAS REGULADORAS NA FRANÇA E NO BRASIL}

Dentre as redes sociotécnicas submetidas a mudanças nos marcos regulatórios, destaca-se no Brasil e na França, o setor de telecomunicações. Segundo estudos do IPEA, algumas grandes tendências se colocam no setor e que explicam este papel-chave nos processos de desestatização: i) difusão acelerada das tecnologias da informação e comunicação que viabilizam novos mercados e novas formas de concorrência; ii) utilização das telecomunicações como vantagem competitiva; iii) revisão das estratégias empresariais dos atuais operadores e dos newcomers; iv) revisão do seu modo de regulamentação.

\subsection{Telecomunicações: ANATEL (Brasil) e ART} (França) frente às missões de serviço público

Em consonância com o objeto central deste trabalho - as agências reguladoras e suas relações com o poder concedente - deter-nos-emos na análise das Leis $\mathrm{n}^{\circ} 9.472$ de 16 de julho de 1997 e n ${ }^{\circ} 96-659$ de 26 de julho de 1996 que criam, no Brasil e na França, respectivamente, a ANATEL - Agência Nacional de Telecomunicações e a ART - Autoridade de Regulação das Telecomunicações. A leitura dessas leis de criação parte do seguinte conjunto de indicadores, ora construídos com base na leitura sobre as experiências internacional e nacional (Brasileiro e Aragão, 2000; Smith, 1997a, 1997b, 1997c; Bauby, 1998; Rezende e Paula, 1997a, 1997b, 1998): universalidade; relações entre poder concedente e agência reguladora; independência da agência (composição, mandatos, pessoal, transparência); introdução de competição no mercado (interconexão); contrato; direitos dos usuários; estrutura e política tarifária; pesquisa e capacitação de pessoal; fomento ao desenvolvimento industrial e tecnológico; articulação com a sociedade; arbitragem de conflitos.

\subsubsection{Universalidade (acesso a todos; em regime público ou privado)}

No Brasil, os serviços são classificados como de interesse coletivo e restrito. Quanto ao regime jurídico, em público e privado. Cada modalidade de serviço é destinada à prestação exclusivamente no regime público, privado, ou juntos. O regime público é aquele diretamente prestado ou mediante concessão ou permissão, com atribuição ao prestador de obrigações de universalização e de continuidade, cujas modalidades a União se compromete a assegurar. A Agência regula então as obrigações de universalização - acesso de todos ao serviço, independente de sua localização e condição socioeconômica - e de continuidade dos serviços, de forma ininterrupta, no regime público. As obrigações de universalização são objeto de metas periódicas segundo plano elaborado pela Agência e aprovado pelo Executivo. É criado um fundo de universalização, destinado à cobertura de custos de realização dos serviços.

Na França, a lei de regulação das telecomunicações baseia-se em três principios: (i)serviço público e serviço universal; (ii) liberdade no exercicio das atividades do setor através da competição e; (iii) independência das funções de operação e de regulação. Com respeito à universalidade, a garantia do serviço público e do serviço universal é o primeiro objetivo do Governo. Para zelar pelo cumprimento, foi criada, em 1990, a Comissão Superior dos Serviços Públicos dos Correios e Telecomunicações que reúne representantes das duas casas legislativas. O serviço público garante o respeito aos principios de igualdade, continuidade, adaptabilidade e compreende: o serviço universal de telecomunicações (telefone, cabines, catálogo e serviço de informação, em todo o território a preço acessível, cujas obrigações tarifárias assegurem o acesso a todos e se necessário tarifas específicas para certas categorias, evitando discriminação baseada na localização geográfica); serviços obrigatórios de tele-comunicações (telex, telefonia vocal, transmissão de dados, acesso à rede digital são fornecidos em todo território); tarifas são livres no respeito aos princípios do serviço público; 
missões de interesse geral (segurança, ensino superior, pesquisa pública, são asseguradas pelo Estado, ministradas por ele ou para ele).

\subsubsection{Relações entre poder concedente e agência reguladora}

No Brasil, a Lei de criação da ANATEL define que compete à União através do Ministério das Comunicações estabelecer as diretrizes para o setor, através da aprovação dos planos gerais - de outorga das concessões ao setor privado - e de metas com vistas à universalização, estabelecer limites à participação estrangeira no capital da prestadora de serviço, definir a prestação do serviço no regime público ou privado. Compete ainda à União: garantir à população o acesso aos serviços, a tarifas e preços razoáveis; estimular a expansão do uso das redes e serviços no território nacional; adotar medidas que promovam a competição e a diversidade dos serviços; fortalecer o papel regulador do Estado; criar oportunidades de investimento e estimular o desenvolvimento tecnológico e industrial em ambiente competitivo; incentivar a concorrência através da abertura de mercados

Quanto ao órgão regulador - ANATEL, vinculada ao Ministério das Comunicações, baseando-se nos princípios de atuação com independência, imparcialidade, impessoalidade, legalidade, publicidade, compete-lhe: implementar a política nacional de telecomunicações; expedir normas para outorga, prestação e fruição dos serviços no regime público; editar atos de outorga e extinção de direito de exploração; celebrar e gerenciar contratos de concessão e fiscalizar a prestação do serviço; controlar, acompanhar e proceder à revisão de tarifas, fixando-as e homologando reajustes; expedir e extinguir autorização para prestação de serviço no regime privado; gerenciar conflitos de interesses entre prestadores de serviço; exercer as competências legais em matéria de controle das infrações de ordem econômica, ressalvadas aquelas pertencentes ao CADE; arrecadar e aplicar suas receitas; resolver quanto à celebração, alteração ou extinção de seus contratos; formular ao Ministério de Comunicações proposta de orçamento.

Na França, a divisão de competências em matéria de regulação dá amplos poderes ao Ministério de tutela. $\mathrm{O}$ da Economia, Finanças e Indústria detém: (i) a preparação dos projetos de lei, decretos e regulamentos; (ii) o controle do serviço público e; (iii) o acompanhamento da France Telecom. São ainda competências do Ministério a fixação das regras do jogo, a negociação das regulamentações internacionais e comunitárias, a preparação das leis e decretos, o controle do serviço público e do serviço univer- sal. O Ministério poderá, se o desejar, fazer apelo às competências da ART.

A aplicação das regras do jogo repousa na ART, cujo papel é de assegurar: o bom funcionamento do mercado e da concorrência, preservando os interesses dos utilizadores, e a manutenção do serviço público em ambiente concorrencial; a transição de um mercado monopolístico para uma concorrência efetiva; a passagem obrigatória que constitui para todo novo operador a interconexão à rede universal existente.

Assim, a ART detém poderes limitados, estando ao encargo de: instrução das demandas de licenças, incluindo a preparação de autorização das redes abertas ao público, depositadas pelos operadores, inclusive France Telecom, sendo que, a atribuição das licenças em sí é da competência do Ministério; interconexão, aprovando o catálogo de interconexão dos operadores inclusive a proposta de France Telecom; frequências, atribuindo aos operadores os recursos em matéria de frequências, números e direitos de passagens; litígios, resolvendo-os nos domínios da interconexão e da repartição das infraestruturas (direitos de passagem, acesso aos pontos altos), zelando pela igualdade de tratamento dos operadores de serviços internacionais (sistemas de cabos submarinos, organizações por satélites); poder de dar pareceres quanto às tarifas do serviço universal e dos serviços sob monópolio de fato, de propor as contribuições devidas para o financiamento do serviço universal, isto é, o cálculo das contribuições a serem pagas pelos operadores para o financiamento dos serviços; poder de sanção, aplicando multas quando a regulamentação não for respeitada; fazendo apelo ao Conselho da Concorrência, exercendo papel de mediação e de conciliação sobre os diferentes litígios; transparência dos mercados e informação dos atores, com o envio anual de relatório dirigido ao Governo e ao Parlamento, em que pode sugerir modificações legislativas ou regulamentares para a evolução do setor e desenvolvimento da concorrência; regulação técnica, com o papel de gestão do plano de numeração e alocação de recursos aos operadores - atribuição de frequências, acordo de equipamentos; definição de regras técnicas.

Ainda, a ART é consultada quando dos projetos de lei ou de regulamentação e participa sob demanda do Ministério das negociações internacionais e comunitárias no setor.

\subsubsection{Independência da agência: composição, mandatos, pessoal}

A composição da ANATEL é a seguinte: Conselho Diretor, Conselho Consultivo, Procuradoria, Corregedoria, Biblioteca, Ouvidoria. O Conselho Dire- 
tor é composto por cinco conselheiros e decide por maioria de votos. Suas competências são: aprovar normas próprias de licitação e contratação; propor o estabelecimento e alteração das políticas de governo; editar normas sobre matérias de competência da Agência; aprovar editais de licitação, homologar adjudicações, decidir pela prorrogação, transferência, intervenção e extinção, em relação às outorgas para a prestação do serviço no regime público; aprovar o plano de autorizações de serviço prestado no regime privado; autorizar a contratação de serviços de terceiros, ficando vedada a realização por terceiros da fiscalização de competência da Agência.

Os conselheiros devem ser brasileiros, possuir formação universitária e elevado conceito em sua especialidade, sendo escolhidos pelo Presidente da República e por ele nomeados, após aprovação pelo Senado Federal. Os mandatos serão de 3, 4, 5, 6, 7 anos estabelecidos no decreto de nomeação. Os membros somente perderão o mandato em virtude de renúncia, de condenação judicial ou de processo administrativo. Aos conselheiros é vedado o exercício de qualquer outra atividade profissional, empresarial, sindical ou de direção político-partidária, salvo a de professor universitário, em horário compatível. É vedado aos conselheiros ter interesse significativo, direto ou indireto, em empresa relacionada com telecomunicações. Até um ano após deixar o cargo, é vedado ao ex-conselheiro representar pessoas ou interesses perante a Agência.

Quanto ao Conselho Consultivo, a idéia é que seja um órgão de participação institucionalizada da sociedade, integrado por representantes indicados pelo Senado, Câmara dos Deputados, Poder Executivo, entidades de classe das prestadoras de serviços, entidades dos usuários e da sociedade. $\mathrm{O}$ presidente é eleito por seus membros e tem mandato de um ano. Os membros do Conselho não serão remunerados, terão mandato de 3 anos, vedada a recondução. Os mandatos dos primeiro membros serão de um, dois e três anos, na proporção de um terço para cada período. O Conselho será renovado anualmente em um terço. São competências do Conselho Consultivo: apreciar os relatórios anuais do Conselho Diretor, aconselhar quanto à instituição ou eliminação da prestação de serviço no regime público, opinar sobre o plano geral de outorgas e o plano geral de metas para universalização.

Na França, a ART é composta por cinco membros nomeados por um mandato de seis anos, em razão de suas qualificações nos domínios jurídico, técnico e de economia dos territórios. Três membros, incluindo o presidente, são nomeados por decreto. Os outros dois são nomeados pelos Presidentes da Assembléia Nacional e do Senado. A ART delibera por maioria, mas com um mínimo de três membros presentes. A duração dos mandatos é escalonada, os três nomeados por decreto têm mandato de seis (presidente), quatro e dois anos. Os outros dois são nomeados pelo Poder Legislativo, têm mandatos de quatro e seis anos, um e outro. Os mandatos não são renováveis. Os membros não podem ter mais de 65 anos, não podem exercer outra atividade profissional, nem ser membros da Comissão Superior do Serviço Público.

\subsubsection{Competição}

No Brasil, segundo a lei, os serviços são organizados com base no princípio da livre, ampla e justa competição entre as prestadoras, devendo o poder público atuar para propiciá-la, bem como corrigir os efeitos da competição imperfeita. Os atos que visem qualquer forma de concentração econômica (fusão, incorporação de empresas) ficam submetidos à apreciação do CADE. São coibidos os comportamentos prejudiciais à competição, no regime público ou privado; a prática de subsídios para redução artificial de preços; o uso, objetivando vantagens na competição, de informações obtidas dos concorrentes, em virtude de acordos de prestação de serviço; a omissão de informações técnicas e comerciais relevantes à prestação de serviço. Visando propiciar competição e impedir a concentração, a Agência poderá estabelecer restrições e limites a empresas ou grupos empresariais quanto à obtenção e transferência de concessões, permissões ou autorizações.

$\mathrm{Na}$ França, um dos principios da lei é reforçar a competitividade da economia, favorecendo o desenvolvimento de uma indústria de serviços e de equipamentos. As regras do jogo devem ser claras e previsiveis, tanto para France Telecom quanto para seus concorrentes. Para garantir a competição, a questão da interconexão é central. A lei garante que todo operador da rede pública ou prestador de serviço público telefônico, terá direito a interconexão às redes a que eles demandem acesso.

\subsubsection{Contrato}

No Brasil, as concessões são outorgadas mediante licitação disciplinada pela Agência. O contrato da concessão indicará: objeto, área, prazo da concessão; modo, forma e condições da prestação do serviço; regras e parâmetros definidores da implantação; deveres relativos à universalização e à continuidade do serviço; valor devido pela outorga, forma e condições de pagamento; tarifas a serem cobradas aos usuários e os critérios para seu reajuste e revisão; direitos, garantias e obrigações dos usuários, da Agência e da concessionária; forma da prestação de contas e da físcalização. O prazo máximo da concessão será de 20 anos, podendo ser prorrogado, uma única 
vez, por igual período, desde que a concessionária tenha cumprido as condições da concessão e manifeste expresso interesse na prorrogação, pelo menos, trinta meses antes de sua expiração. A exploração do serviço no regime público dependerá de prévia outorga, pela Agência, mediante concessão. A concessão é uma delegação mediante contrato, por prazo determinado, no regime público, sujeitando-se a concessionária aos riscos empresariais, remunerando-se pela cobrança de tarifas dos usuários ou por outras receitas alternativas. As concessões não terão caráter de exclusividade, devendo obedecer ao plano geral de outorgas com definição quanto à divisão do país em áreas, número de prestadores, prazos de vigência e para admissão de novos prestadores.

$\mathrm{Na}$ França, o serviço universal das telecomunicações é operado por uma grande quantidade de empresas (uma delas France Telecom) a partir de autorizações emitidas pelo Ministério (e não pela Agência) segundo cláusulas contratuais (cahier des charges) versando sobre: características da zona de cobertura; condições de qualidade, disponibilidade, modos de acesso às redes; confidencialidade e neutralidade das mensagens transmitidas; normas e especificações das redes, sobretudo européias; prescrições relativas à defesa do meio ambiente; segurança pública; fornecimento de informações; direitos e obrigações dos operadores em matéria de interconexão; condições necessárias para uma concorrência leal; obrigações do operador para permitir o controle dos cahier des charges pela Agência. O cahier des charges é estabelecido após parecer da Comissão Superior do Serviço Público dos Correios e Telecomunicações definindo as condições gerais de fornecimento deste serviço e as obrigações tarifárias, evitando as discriminações de caráter financeiro ou geográfico. A autorização é dada por 15 anos. Dois anos antes da expiração do contrato, o Ministério notifica ao titular as condições de renovação da autorização ou os motivos de sua recusa.

\subsubsection{Direitos dos usuários}

No Brasil, a Lei busca garantir aos usuários o acesso aos serviços, com padrões de qualidade, regularidade, em qualquer ponto; a liberdade de escolha de sua prestadora de serviço; as informações adequadas sobre tarifas, preços e condições de prestação dos serviços; a inviolabilidade e segredo de sua comunicação; a não suspensão do serviço, salvo por débito e descumprimento dos contratos, mas tendo prévio conhecimento; a resposta às reclamações pela prestadora do serviço; e o direito de peticionar contra a prestadora perante o órgão regulador e os organismos de defesa do consumidor. A bibliografia disponível sobre a matéria na França não esclarece os direitos dos usuários.

\subsubsection{Pesquisa e capacitação de pessoal}

No Brasil, é proposta a criação de um fundo para o desenvolvimento tecnológico das telecomunicações brasileiras, com o objetivo de estimular a pesquisa e o desenvolvimento de novas tecnologias, incentivar a capacitação dos recursos humanos, fomentar a geração de empregos e promover o acesso de pequenas e médias empresas a recursos de capital, de modo a ampliar a competição na indústria de telecomunicações.

$\mathrm{Na}$ França, o ensino superior no domínio das telecomunicações é da responsabilidade do Estado sob a tutela do Ministério. As atividades de pesquisa são exercidas pelo Estado ou em seu nome, através de contratos que definem os programas, as modalidades de sua realização e os meios financeiros.

\subsubsection{Tarifas}

No Brasil, compete à Agência estabelecer a estrutura tarifária para cada modalidade do serviço. As tarifas são fixadas no contrato de concessão, consoante edital ou proposta apresentada na licitação. Transcorridos ao menos três anos da celebração do contrato, a Agência poderá, se existir ampla e efetiva competição entre as prestadoras do serviço, submeter a concessionária ao regime de plena liberdade. É criado o Fundo de Fiscalização das Telecomunicações - FISTEL, que recebe o produto da arrecadação das taxas de fiscalização de instalação e de funcionamento. A agência submete anualmente ao Ministério a sua proposta de orçamento, e a do FISTEL.

\subsubsection{Fomento ao desenvolvimento industrial}

No Brasil e na França, embora se saiba do papel das telecomunicações para o desenvolvimento industrial dos países, não é claramente visível nas leis a importância deste processo de privatização para o desenvolvimento econômico. Isto remete a uma questão maior, qual seja, a de saber em que medida os novos marcos regulatórios em andamento nos dois países - expressos nos programas de privatização, de descentralização, de passagem dos serviços públicos ao setor privado - se articulam ou servem de alavanca para o desenvolvimento econômico dos países.

\subsubsection{Articulação com a sociedade}

No Brasil e na França, a participação dos diversos segmentos da sociedade nas Agências não é muito clara, a não ser pela existência da figura do ouvidor (Brasil), que é, em si, insuficiente. Na França, pelo menos na documentação examinada, a questão nem se coloca. 


\subsubsection{Arbitragem de conflitos}

No Brasil e na França, fica ao encargo da ANATEL e da ART arbitrar os conflitos que surjam envolvendo os atores mais diretamente envolvidos com o setor: usuários e concessionários.

\subsection{Transportes: a agência regulatória brasileira frente aos desafios da competição}

No Brasil, o processo de privatização das infra-estruturas foi acompanhado, a exemplo do caso inglês, da criação de agências reguladoras. Estas têm, dentre outros aqui já vistos, os objetivos de garantir o cumprimento das cláusulas contratuais com as concessionárias privadas, bem como a qualidade dos serviços prestados à população e a efetiva introdução da competição.

No caso dos transportes, somente no final do ano 2001, dois anos depois de concedida a operação da malha ferroviária, foi aprovado no Congresso Nacional, a criação das agências reguladoras: a ANTT - Agência Nacional de Transportes Terrestres e a ANTAQ - Agência Nacional de Transporte Aquaviário. Foram ainda criados o CONIT - Conselho Nacional de Integração de Políticas de Transportes e o DNIT - Departamento Nacional de InfraEstrutura de Transportes.

Com relação à divisão de competências, observase uma certa superposição entre as funções destes vários organismos, que, se não forem devidamente esclarecidas, poderão influir na perda de eficiência e de eficácia do setor como um todo. Senão vejamos. Segundo a Lei ${ }^{\circ} 10.233$, o CONIT é um organismo vinculado diretamente à Presidência da República, com atribuições de propor ao Presidente, políticas nacionais de integração e de harmonização dos transportes aéreo, aquaviário e terrestre, harmonizando as respectivas políticas setoriais. Estabelece ainda as diretrizes para a integração física dos transportes nos níveis federal, estadual e municipal; promove a competitividade do setor com vistas à redução de custos, tarifas e fretes; define políticas de apoio ao desenvolvimento tecnológico; define medidas de logística do transporte multimodal; além de propor ao Poder Executivo e ao Congresso Nacional reformulações do Sistema Viário Nacional, que julgue adequadas. Neste contexto, que atribuições restam ao poder concedente, o Ministério dos Transportes?

Com relação às Agências Reguladoras, são seus objetivos: implementar, em suas respectivas esferas de atuação, as políticas formuladas pelo CONIT e pelo Ministério dos Transportes - sem que se esclareça onde estão as atribuições deste último; regular ou supervisionar as atividades de prestação de serviços e de exploração da infra-estrutura de transportes, exercida por terceiros. Especificamente, para efeitos deste trabalho, constituem a esfera de atuação da ANTT: o transporte ferroviário de passageiros e de cargas; a exploração da infra-estrutura ferroviária e o arrendamento dos ativos operacionais correspondentes; o transporte rodoviário interestadual e internacional de passageiros; o transporte rodoviário de cargas; a exploração da infra-estrutura rodoviária federal submetida ao regime de concessões; o transporte multimodal; o transporte de cargas especiais e perigosas em ferrovias e rodovias.

Definem-se ainda como atribuições da ANTT: promover pesquisas e estudos de tráfego e de demanda, estudos com vistas à definição das tarifas, à sua revisão e ao seu reajuste, após prévia comunicação ao Ministério da Fazenda; propor ao Ministério dos Transportes os planos e os instrumentos de outorga para exploração da infra-estrutura e de prestação dos serviços; promover estudos sobre a logística do transporte intermodal; habilitar o operador do transporte intermodal.

Cabe à ANTT, como atribuições específicas pertinentes ao transporte ferroviário: publicar os editais, julgar as licitações, celebrar e administrar os contratos de concessão para a prestação dos serviços e para construção e exploração de novas ferrovias; fiscalizar o cumprimento das cláusulas contratuais de prestação dos serviços e de manutenção e reposição dos ativos arrendados; regular e coordenar a atuação dos concessionários, assegurando neutralidade com relação aos interesses dos usuários, orientando e disciplinando o tráfego mútuo de passagem. É de sua competência ainda o estímulo à formação de associações de usuários, no âmbito de cada concessão ferroviária para a defesa de seus interesses.

A estrutura básica da ANTT é composta por um Diretor-Geral e quatro Diretores, nomeados pelo Presidente da República após aprovação pelo Senado. Eles cumprem mandatos de quatro anos, não coincidentes, admitida uma recondução. A eles é vedado o exercício de qualquer outra atividade profissional, empresarial, sindical ou de direção políticopartidária. Até um ano após deixar o cargo, é vedado ao ex-Diretor utilizar informações privilegiadas, obtidas em decorrência do cargo exercido.

Ainda pela mesma lei, o DNIT tem como objetivo implementar - com exceção das infra-estruturas concedidas ou arrendadas pela ANTT e ANTAQ - a política formulada pela administração da infra-estrutura do Sistema Federal de Viação. O DNIT administra então os programas de operação, manutenção, conservação, restauração e reposição de rodovias, ferrovias, vias navegáveis, terminais e instalações portuárias, não submetidas ao processo de concessão e pedágio. 
5 QUE ENSINAMENTOS? FORÇAS E FRAQUEZAS DAS TUTELAS

Procedendo a uma primeira tentativa de interpretar as reformas regulatórias no Brasil e na França e, em especial, as divisões de competências entre as agências e poder concedente, e sem incluir um estudo da real aplicação dos regulamentos, têm-se as seguintes questões:

Como se coloca a universalidade? Como se definem os papéis e as competências do poder concedente (União) e do órgão regulador? E de ambos frente aos concessionários? As Leis propiciam efetivamente a introdução da concorrência no setor? Em que medida há maior ou menor independência do órgão regulador frente ao poder de tutela e aos concessionários privados? Que mecanismos são previstos para garantir a qualidade do serviço e a proteção dos direitos dos usuários? Como se prevê a participação da sociedade?

\subsection{As telecomunicações do Brasil e da França frente às missões de serviço público}

A universalidade no acesso às telecomunicações, em ambos os países, em consonância com sua tradição de Estados intervencionistas, colocam claramente as missões de serviço público. Mas há uma diferença essencial quanto à prática. Na França, a Agência tem bem menos poder que no Brasil. Com efeito, na França, as missões de estabelecer diretrizes, definir as políticas, os contratos, as tarifas, as autorizações e licenças para os operadores atuarem são atribuições do Ministério. No Brasil, embora seja dito que a Agência implementa a política de telecomunicações, na prática, ela faz muito mais, pois define as tarifas, celebra e gerencia os contratos. Logo, a definição das competências está muito mais clara na França, onde a Agência tem um papel complementar às missões de serviço público que estão nas mãos do Ministério.

Quanto aos papéis do Poder de tutela e do órgão regulador, está presente nas Leis de ambos os países a preocupação com a independência do órgão regulador frente ao poder de tutela com relação a: objetivos (implantar a política nacional); processo decisório (escalonamento dos mandatos dos dirigentes); instrumentos (organizar as concessões precedidas de licitações, fixar tarifas); financeira (taxa de fiscalização dos serviços). Mas também em relação aos concessionários (competências em matéria de evitar abusos econômicos) e ainda na preservação dos direitos dos usuários. Não está claro, todavia, como estes últimos expressam suas necessidades.

Quanto à relação entre poder de tutela e órgão regulador de um lado, e concessionários de outro, há que se ter em conta - em ambos os países - a existência de assimetria de informações, devendo-se prever mecanismos para evitar o desequilíbrio entre os níveis de informação de cada uma dos atores. Mas na França, há uma diferença essencial, devido à presença do operador histórico, France Telecom, no qual o Estado detém maioria das ações, tendo conseguido fortalecê-la a ponto desta passar a disputar e operar mercados mundiais. Assim, pelos seus padrões de qualidade ela pode se constituir em uma referência na definição dos indicadores de avaliação dos demais operadores privados.

Quanto aos aspectos ligados à introdução de competição no setor, ambas as Leis são claramente feitas com este espírito. Necessário se faz analisar com profundidade o novo perfil que se desenha para o setor, após os processos licitatórios que ocorreram na telefonia celular e que virão nos demais segmentos. Sabe-se que a competição tem uma dimensão fortemente cultural, e que o Brasil e a França apenas agora começam a dar os seus primeiros passos. No caso francês, há que se ter o cuidado de garantir que os operadores privados tenham os mesmos direitos e deveres que o operador histórico.

A independência das Agências frente ao próprio poder de tutela e, sobretudo, frente aos concessionários privados, é por demais ressaltada em ambas as Leis. São inclusive previstos mecanismos semelhantes para a escolha dos dirigentes, a exemplo dos prazos de mandatos. Mas uma diferença essencial é que na França, a Agência é obrigada a prestar contas tanto ao Ministério de tutela, quanto à Comissão Superior dos Serviços Públicos dos Correios e Telecomunicações. No Brasil, a Agência tem concentrado poderes excessivos, não estando claros os mecanismos de controle sobre suas atividades. seja da parte da tutela seja da parte sociedade.

\subsection{Os transportes do Brasil e da França frente às missões de serviço público}

Quanto à universalidade, ambos os países, como já visto, explicitam claramente a missão de serviço público. Mas há uma diferença essencial quanto à prática desta missão. Na França, nos transportes, não se criou Agência Reguladora, ao contrário do Brasil, e, as missões de estabelecer diretrizes, definir as políticas, os contratos, as tarifas, as autorizações e licenças para os operadores atuarem são atribuições diretas do Ministério dos Transportes.

No Brasil, embora dito que a Agência reguladora implementa a política de transportes, na prática, ela faz muito mais, pois define as tarifas, celebra e gerencia os contratos. Ademais, cria-se ainda o CONIT que também estabelece diretrizes de políticas de transportes, podendo esvaziar, na prática, as 
atribuições do Ministério dos Transportes, enquanto poder concedente definido pela Constituição Federal. Em síntese, um quadro pouco claro, emerge da Lei específica. A definição das competências está muito mais clara na França, e as missões de serviço público estão sob a responsabilidade do Ministério, enquanto a operação e manutenção das infra-estruturas estão sob a responsabilidade de duas empresas públicas, atuando segundo padrões definidos para o setor privado.

Quanto à relação entre poder concedente e órgão regulador de um lado, e concessionários de outro, há que se ter em conta - em ambos os países - a existência de assimetria de informações, devendo-se prever mecanismos para evitar esse desequilíbrio. Mas na França, há também uma diferença fundamental: a presença da SNCF, estatal, fortalecida pelo Governo a ponto de disputar mercados em outros países europeus. De modo que, pelos seus padrões de qualidade, ela pode se constituir em uma referência na definição dos indicadores de avaliação dos operadores privados de outros países, a exemplo das ferrovias inglesas.

Assim, no caso francês, se de um lado, ficaram bem mais claras - constituindo mesmo um avanço as relações entre o organismo de tutela, o Ministério, o organismo encarregado das infra-estruturas, a RFF e o operador histórico, a SNCF, de outro lado, permanece latente a participação social nos processos de decisão do setor. Se as paralisações recentes dos sindicatos ferroviários têm sido motivada, sobretudo, por razões salariais, não deixam de ser um sinal da necessidade de abrir canais e instrumentos de participação dos diversos segmentos da sociedade nos processos de decisão das grandes redes sociotécnicas.

Quanto aos aspectos ligados à introdução de competição no setor, ambas as reformas regulatórias são feitas com este espírito. Necessário se faz analisar, com profundidade, o novo perfil que se desenha para o setor. No caso francês, ainda não se observa a existência de competição pelo uso, por exemplo, dos trilhos por outras empresa européias. A SNCF, agora regida segundo moldes de empresa privada, mantém o monopólio público da operação dos serviços ferroviários.

O caso brasileiro é sério, pois as concessões da operação dos transportes ferroviários de carga ocorreram há cinco anos, e ainda hoje o poder público não dispõe de capacidade técnica e profissional para fiscalizar as cláusulas contratuais, nem de instrumentos técnicos e jurídicos para proceder à necessária fiscalização e aplicações de sanções aos concessionários, no caso de não cumprimento dos contratos.

\section{DESAFIOS E PERSPECTIVAS}

Constitui-se um desafio histórico a criação de mecanismos e instrumentos adequados para cumprir as finalidades de serviço público em que as redes de comunicações estão imbuídas. Para, isto, é fundamental, o envolvimento da sociedade.

No contexto das reformas regulatórias em andamento, há que se discutir as grandes orientações de políticas de transportes e telecomunicações que mais bem atendam às características sociais e econômicas dos países. Na França, o desafio consiste em manter a firme presença do Estado enquanto operador das redes nacionais de transportes, telecomunicações, energia, correios e gás, mantendo os princípios do serviço público universal, mas em um ambiente europeu que incentiva a competição no interior dos mercados. O desafio francês consiste em saber até quando os regimes de monopólios públicos resistem às pressões da comunidade européia. Esta resistência será tanto mais duradoura quanto melhor for a qualidade dos serviços prestados à população e quanto mais a sociedade se identificar com estes serviços, que devem ser vistos como conquistas suas.

No Brasil, os desafios são bem maiores. Isto por causa das enormes desigualdades econômicas e sociais herdadas das opções de políticas de desenvolvimento. $\mathrm{E}$ as infra-estruturas em rede estão no centro desta crise. Há que se debater que políticas infra-estruturais são as mais adequadas para a realidade brasileira. Se o desafio maior consiste, por exemplo, em mudar a matriz de transportes - hoje centrada no modo rodoviário - orientando-a para uma retomada dos investimentos no ferroviário, a perspectiva é de que o atual momento de debates sobre as opções de sociedade, possa constituir-se em um espaço real de reflexão e de decisão sobre as reformas nos transportes de que a população necessita. Da mesma forma, no caso da telefonia fixa, o desafio consiste em colocar um aparelho em funcionamento em qualquer parte do território nacional, de modo que qualquer cidadão, independente de sua condição de renda, possa ter acesso em qualquer hora do dia ou da noite.

Em conclusão, o ponto central, tanto na França quanto no Brasil, gira em torno da necessidade de uma regulação que não seja puramente técnica, mas sim ampliada para uma regulação pelo conjunto dos atores da sociedade. Isto porque a simples existência de regras, de normas, não garante a boa qualidade dos serviços prestados aos usuários: um dos alvos importantes e fundamentais da regulação. 


\section{REFERÊNCIAS}

Aragão, J. (1998) O novo Direito Concessionário nacional: e agora, ônibus brasileiro? In CNT/ANPET (orgs.) Transporte em transformação. Makron, Brasília. p. 26-51.

Bauby, P. (1998) Services publics: de la tutelle à la régulation. In Flux, n. 31-32, p. 25-33.

Bergougnoux, J. (Rapport présidé par) (2000) Services publics en réseau : perspectives de concurrence et nouvelles régulations. La Documentation Française, Paris.

Brasileiro, A. e E. Henry (orgs.) (1999) Viação Ilimitada. Ônibus das cidades brasileiras. Cultura, São Paulo.

Brasileiro, A. e J. Aragão (2000) Agências regulatórias: que contribuições do (ao) setor de transportes no Brasil? In Santos, E. e J. Aragão (orgs.) Transporte em tempos de reforma. Ensaios sobre a problemática. LGE, Brasília, p. 233-260.

Caron, F. (1997) Histoire des chemins de fer en France, 1740 1883. Fayard, Paris.

Coutard, O. (dir.) (1998) The governance of large technical systems. Routledge, New York.

Curien, N. (2000) Economie des réseaux. La Découverte, Paris.

Flichy, P. (1997) Une histoire de la communication moderne. Espace public et vie privée. La Découverte, Paris.

Garièpy, M. e M. Marie (1997) Ces réseaux qui nous gouvernent? L'Harmattan, Paris.

Lévèque, F. (1998) Économie de la réglementation. La Découverte, Paris.
Musso, P. (1997) Telécommunications et philosophie des réseaux. PUF, Paris.

Orrico Filho, R. et al. (1996) Ônibus urbano. Regulamentação e mercados. LGE, Brasília.

Quin C. e G. Jeannot (1997) Un service public pour les européens? Diversité des traditions et espaces de convergente. La Documentation Française, Paris.

Rezende, F. e T. B. Paula (orgs.) (1997a) Infra-estrutura: perspectivas de reorganização. Telecomunicações. IPEA, Brasília Rezende, F. e T. B. Paula (orgs.) (1997b) Infra-estrutura: perspectivas de reorganização. Regulação. IPEA, Brasília

Rezende, F. e T. B. Paula (orgs.) (1998) Infra-estrutura: perspectivas de reorganização. Transportes. IPEA, Brasília

Ribeill, G. (1993) La révolution ferroviaire. Bélin, Paris.

Smith, W. (1997a) Utility regulators. The independence debate. Public Policy for the Private Sector, note 127. The World Bank, Washington, DC.

Smith, W. (1997b) Utility regulators. Roles and responsabilities. Public Policy for the Private Sector, note 128. The World Bank, Washington, DC.

Smith, W. (1997c) Utility regulators. Decision-making structures, resources, and start-up strategies. Public Policy for the Private Sector, note 129. The World Bank, Washington, DC.

Stoffaes, C. (sous la direction de) (1994) L'Europe à l'epreuve de l'intérêt général. Aspe Europe, Paris.

Walrave, M. (1995) Les réseaux de services publics dans le monde. Organisation, régulation, concurrence. Collection Rapports Officiels, Paris. 